\title{
Effects of Deep Cryogenic Treatment on Wear Mechanisms and Microthermal Expansion for the Material of Drive Elements
}

\author{
Yuh-Ping Chang, ${ }^{1}$ Gino Wang, ${ }^{1}$ Jeng-Haur Horng, ${ }^{2}$ Li-Ming $\mathrm{Chu}^{3}$ and Yih-Chyun Hwang ${ }^{4}$ \\ ${ }^{1}$ Department of Mechanical Engineering, Kun Shan University, Tainan 710, Taiwan \\ ${ }^{2}$ Department of Power Mechanical Engineering, National Formosa University, Yunlin 632, Taiwan \\ ${ }^{3}$ Department of Mechanical and Automation Engineering, I-Shou University, Kaohsiung 840, Taiwan \\ ${ }^{4}$ Hiwin Technologies Corp., Taichung 40707, Taiwan
}

Correspondence should be addressed to Yuh-Ping Chang; ypc0318@mail.ksu.edu.tw

Received 15 September 2013; Accepted 2 November 2013

Academic Editor: Shoou-Jinn Chang

Copyright (C) 2013 Yuh-Ping Chang et al. This is an open access article distributed under the Creative Commons Attribution License, which permits unrestricted use, distribution, and reproduction in any medium, provided the original work is properly cited.

By the composite heat treatments, the strength and the surface hardness of the materials of drive elements can be improved. Moreover, the high accurate and capable machines can be obtained. For the numerous composite heat treatments, the deep cryogenic treatment has been used widely for the purpose of low thermal expansion in the industry. Therefore, this paper is further to investigate the low friction, wear resistance, and low thermal expansion for the carburizing steels of drive elements with deep cryogenic treatment. According to the experimental results, martensitic transformation occurred after the deep cryogenic treatment. The effects of deep cryogenic treatment on wear mechanisms are significant. The shape of wear particles changes from slip tongue to smooth stratification. Moreover, the surface magnetization is smaller for the case of Carburizing-Deep cryogenic treatment. Hence, the wear mechanism becomes simple. Besides, the thermal expansion is significantly smaller for the case of Carburizing-Deep cryogenic treatment.

\section{Introduction}

Three attractable problems have been respected over the past decades, such as the fast development of high accurate mechanical engineering, marketability, and energy crisis. Hence, the performance of high reliance and high environmental consciousness is very important for the developments of the tool machines. In order to achieve the above goal, the technology of composite heat treatment is the most important method to improve the surface properties [1,2]. By the composite heat treatments, the strength and the surface hardness of the materials of drive elements can be improved. Therefore, both of low friction and wear resistance can be further completed $[3,4]$.

Many papers about the heat treatment technology had been proposed. Especially, the deep cryogenic treatment has been used widely for the purpose of wear resistance in the industry $[5,6]$. Generally speaking, the drive elements by the deep cryogenic treatment are a wise method for improving the performance of low friction, wear resistance, and low thermal expansion. This can be reasonably explained by that the austenite is one of the unfavorable factors for the microtechnique, such as measuring tool, bearing, and precision optical machinery. Hence, the deep cryogenic treatment [7] and the super cryogenic treatment [8] are always used to make martensitic transformation and improve the wear resistance and the low thermal expansion of the drive elements.

Moreover, since the authors had experimentally studied the wear mechanisms of the pair of iron with the carbon steels in-depth [9-12], the knowledge is applied and adapted to the study of using continuous variation of surface magnetization and friction coefficient for monitoring the tribological properties of the low carbon alloy steel in this paper. Therefore, the effects of the deep cryogenic treatment on wear resistance, and microthermal expansion of the drive elements are investigated in this study. According to the experimental results, the low friction, wear resistance, and low surface magnetization for the drive elements with 


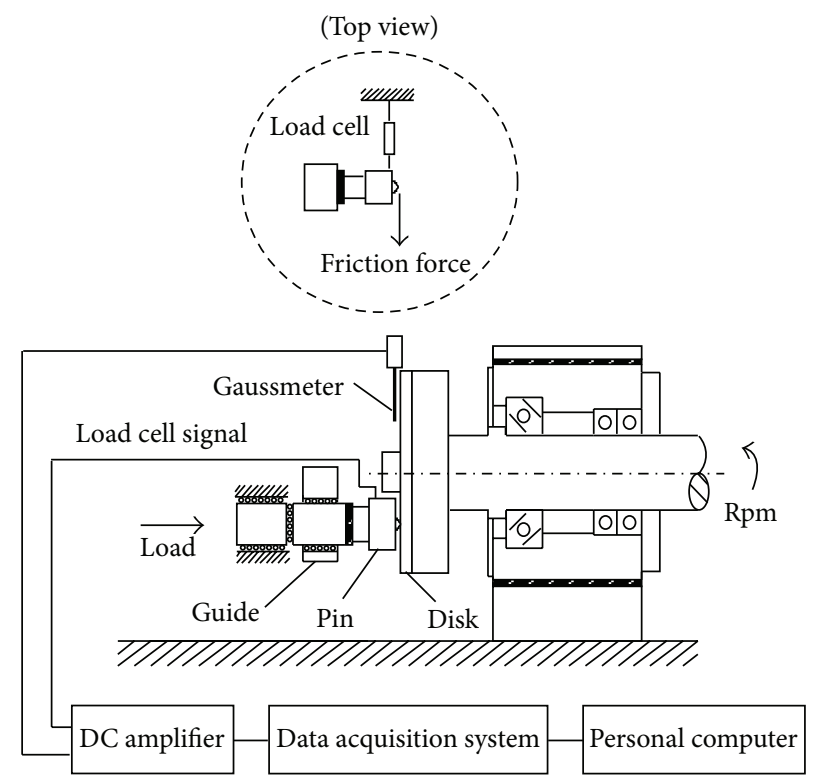

FIGURE 1: Schematic diagram of ball/disk friction tester with the measuring systems.

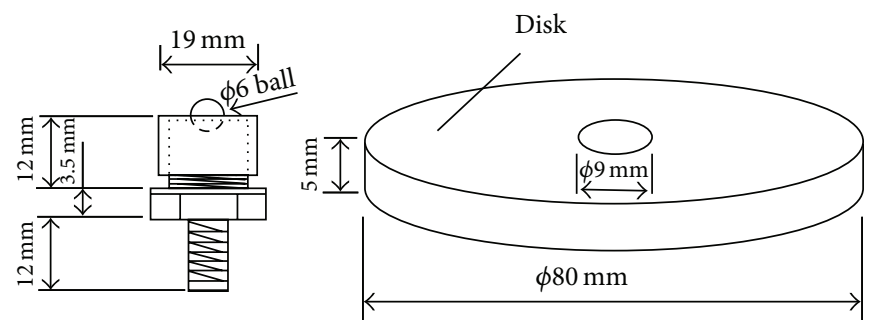

FIGURE 2: The size and shape of the specimen.

the deep cryogenic treatment can be clarified. Moreover, the microwear mechanisms can be investigated by the SEM of the wear particles. Besides, the decreasing of the microthermal expansion will be completed to further develop the tool machines.

\section{Experimental Apparatus and Procedures}

2.1. Experimental Apparatus. The experiments were conducted on a ball/disk friction tester with a measuring system as shown in Figure 1 to investigate the effects of the deep cryogenic treatment on wear resistance of the drive elements under dry severe wear condition. The disk surface was set vertical to the ground to simplify the wear mechanisms. The stationary ball specimen was placed on a rest, connected to a load cell and supported by a set of roller bearings. A load, vertical to the disk surface, was applied to the ball specimen by using the level rule. To avoid impact and to maintain constant contact between the specimens during the friction process, a soft spring $(k=0.17 \mathrm{~N} / \mathrm{mm})$ with an oil damper $(c=1.04 \mathrm{Ns} / \mathrm{m})$ was installed in the loading system. This setup enabled accurate measurement of the friction coefficient between the ball and disk specimens.
In Figure 1, the generated tribomagnetization on the disk surface during the rotating friction process was in the order of $0.1 \mathrm{G}$. The response time of the measuring system was less than $10 \mathrm{~ms}$. Briefly, the instantaneous friction coefficient between the contacting specimens was determined by the voltage signal from the load cell. The variations of surface magnetization were measured by a gauss meter. As the gauss meter probe was situated opposite to the pin specimen, the signal of the tribomagnetization therefore lagged the friction voltage signal by half a cycle. The above two voltages from the load cell and the gauss meter were simultaneously recorded by a data acquisition system and fed to a personal computer for data analysis.

2.2. Test Specimens. The ball specimens were made of SUJ2. Besides, the disk specimens were made of SCM415. Moreover, the disk specimens had been conducted with the different composite heat treatments before the friction tests. The specimens are shown in Figure 2 and their material properties are given in Table 1. Moreover, the surface hardness of the disk specimens with different composite heat treatments is shown in Table 2. 
TABLE 1: Compositions of SCM415.

\begin{tabular}{|c|c|c|c|c|c|c|c|c|}
\hline \multicolumn{9}{|c|}{ SCM415 wt\% } \\
\hline $\mathrm{C}$ & $\mathrm{Si}$ & $\mathrm{Mn}$ & $\mathrm{P}$ & S & $\mathrm{Cr}$ & $\mathrm{Cu}$ & Mo & $\mathrm{Ni}$ \\
\hline $0.13 \sim 0.18$ & $0.15 \sim 0.35$ & $0.6 \sim 0.85$ & $\leqq 0.03$ & $\leqq 0.03$ & $0.9 \sim 1.2$ & $\leqq 0.3$ & $0.15 \sim 0.25$ & $\leqq 0.25$ \\
\hline
\end{tabular}
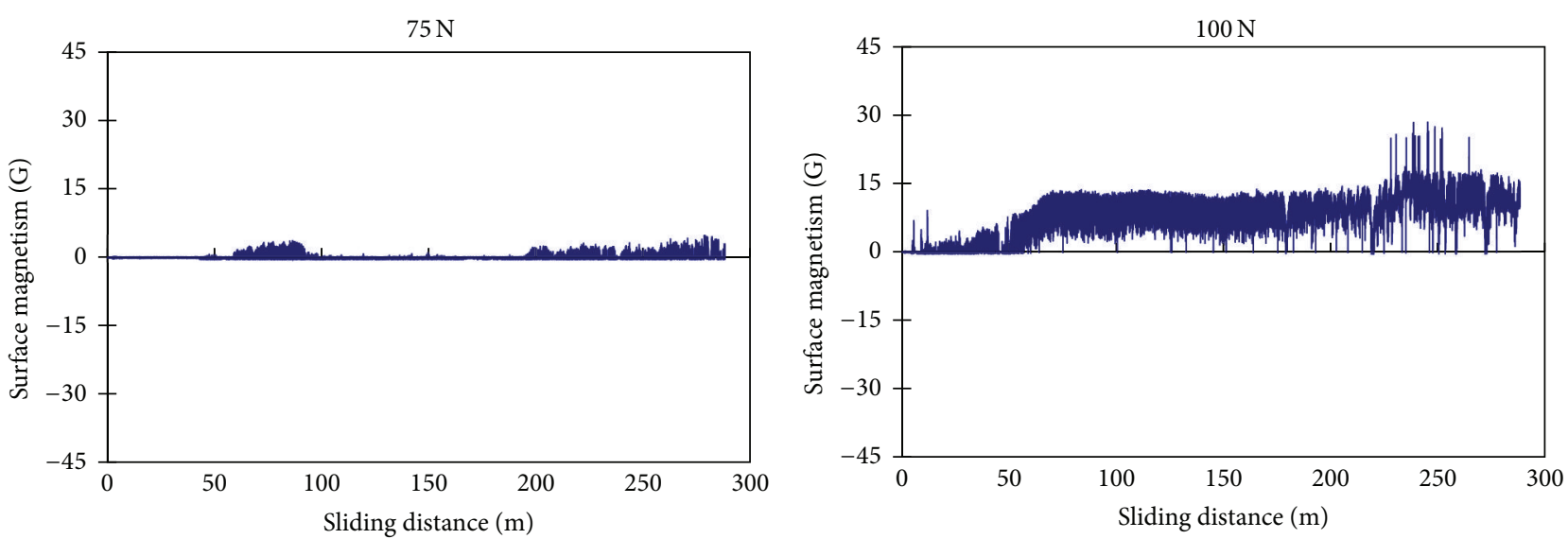

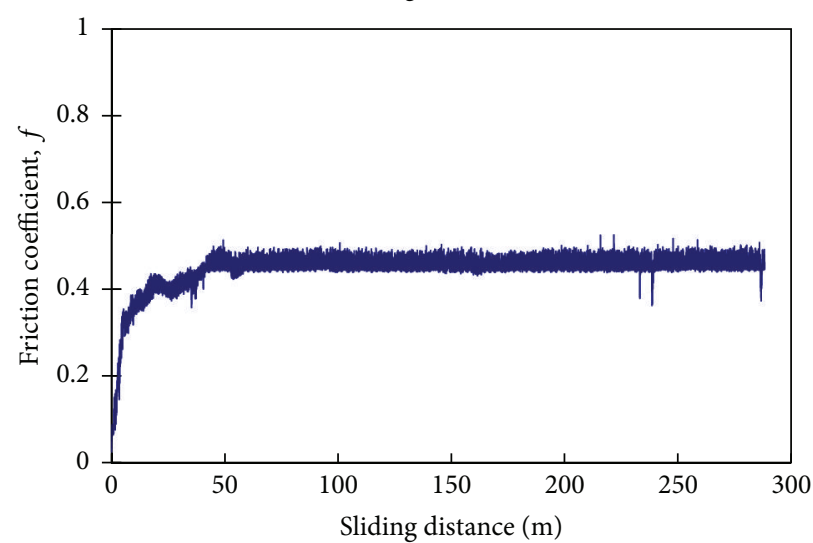

(a)

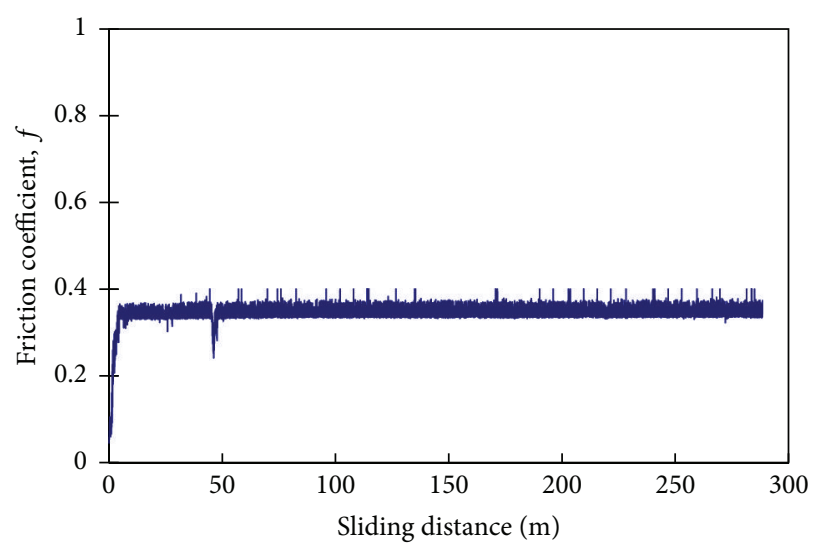

(b)

FIGURE 3: Surface magnetization and friction coefficient responses for SCM415 with Carburizing-Tempering: (a) $75 \mathrm{~N}$ and (b) $100 \mathrm{~N}$.

TABLE 2: Surface hardness of SCM415 with different composite heat treatments.

\begin{tabular}{lc}
\hline Composite heat treatments & Surface hardness (HRC) \\
\hline $\begin{array}{l}\text { Carburizing-Tempering } \\
\text { Carburizing-Deep cryogenic } \\
\text { treatment-Tempering }\end{array}$ & 65.7 \\
\hline
\end{tabular}

2.3. Experimental Procedures. Prior to each friction test the specimens were cleaned with acetone in an ultrasonic cleaner and securely locked in position in the tester. The location and tightness between the ball and the disk interface were of paramount importance to ensure experimental accuracy. As the disk rotated clockwise at a set speed, a normal load was applied to the interface of the specimens.

According to the results [9-12], the wear mechanisms of the pair of iron with the carbon steels transfer during the normal loads from $75 \mathrm{~N}$ to $100 \mathrm{~N}$. Therefore, the sliding speed was fixed at $267 \mathrm{~mm} / \mathrm{s}$ and the normal loads were set as $75 \mathrm{~N}$ and $100 \mathrm{~N}$ in this study. The dynamic variations of friction coefficient and surface magnetization were measured simultaneously during each test. After each test, the wear particles were examined under a SEM. The depth of wear track is measured by means of a surface tester. As the output electric potential from the gauss meter during the rotating friction process was in the order of $\mathrm{mV}$, a DC isolated amplifier was used at a low gain of 25 . The microthermal expansions of the drive elements were measured by a high precision displacement tester. All tests were carried out under dry friction condition. The average room temperature for the test was $23 \pm 2^{\circ} \mathrm{C}$, and the average relative humidity was $65 \pm$ $5 \%$.

\section{Results and Discussions}

Figure 3 shows the typical variations of surface magnetization and friction coefficient with sliding distance produced by 

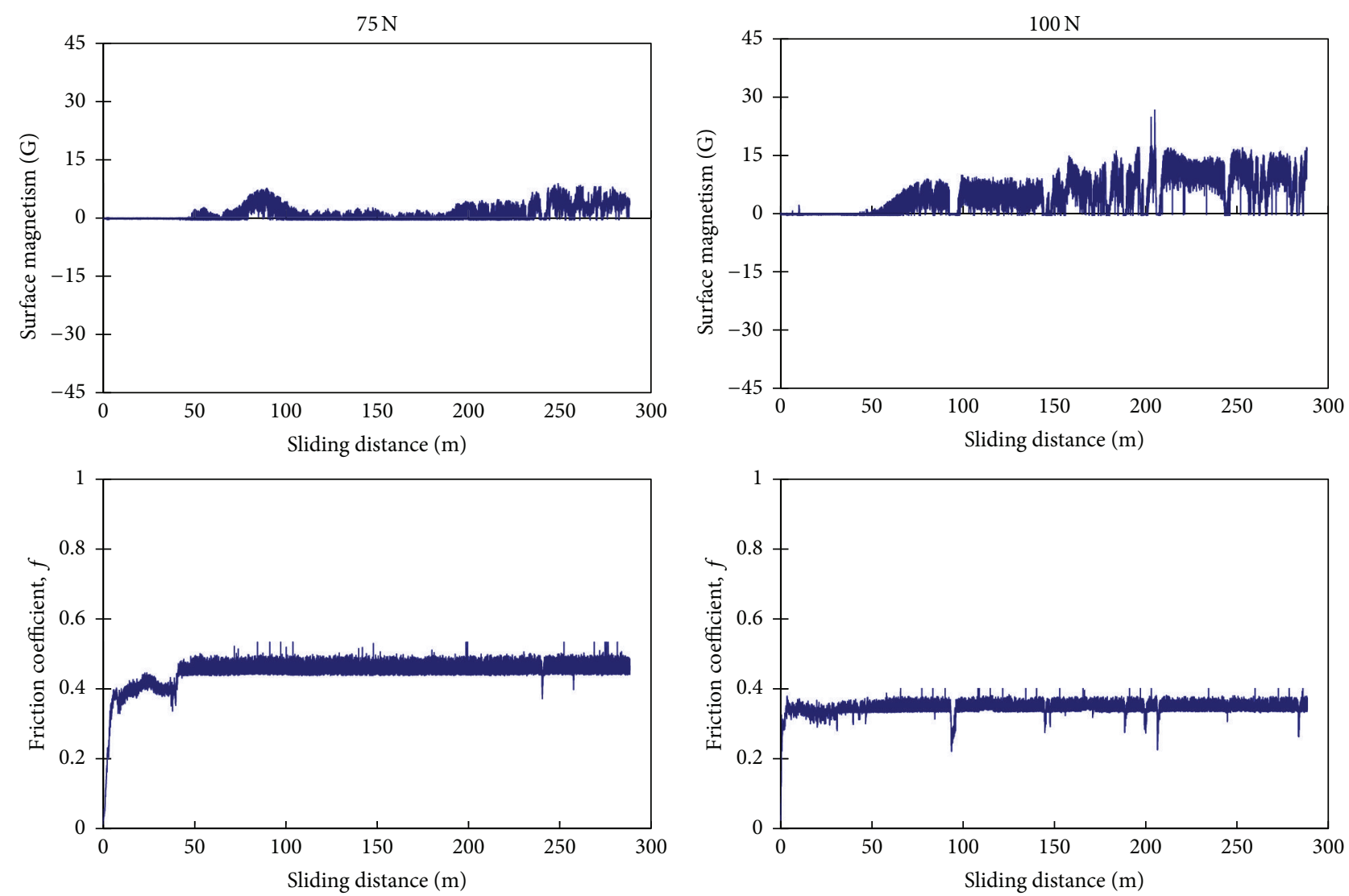

(a)

(b)

FIGURE 4: Surface magnetization and friction coefficient responses for SCM415 with Carburizing-Deep cryogenic treatment-Tempering: (a) $75 \mathrm{~N}$ and (b) $100 \mathrm{~N}$.

the SUJ2 ball sliding on the SCM415 with CarburizingTempering. It is seen from this figure that the average friction coefficient is 0.44 and the maximum surface magnetization is about $4.77 \mathrm{G}$ at $75 \mathrm{~N}$. Moreover, the average friction coefficient is 0.34 and the maximum surface magnetization surges to approximately $28.42 \mathrm{G}$ at $100 \mathrm{~N}$.

The typical variations of surface magnetization and friction coefficient with sliding distance produced by the SUJ2 ball sliding on the SCM415 with Carburizing-Deep cryogenic treatment-Tempering are shown in Figure 4. The average friction coefficient is 0.44 and the maximum surface magnetization is about $8.83 \mathrm{G}$ at $75 \mathrm{~N}$. Moreover, the average friction coefficient is 0.34 and the maximum surface magnetization surges to approximately $26.64 \mathrm{G}$ at $100 \mathrm{~N}$.

Therefore, the effects of deep cryogenic treatment on friction coefficient and surface magnetization are insignificant.

Figure 5 shows the SEM micrographs of wear particle for SCM415 with Carburizing-Tempering. It is seen from this figure that the wear particles show the shape of slip tongue. This indicates that the wear mechanism is ploughing. The size of the larger wear particles reaches $100 \mu \mathrm{m}$ order.

Representative SEM micrographs of wear particle for SCM415 with Carburizing-Deep cryogenic treatment-Tempering are shown in Figure 6. The wear particles are countless and highly concentrated. The size of the larger wear particles reaches $100 \mu \mathrm{m}$ order. Moreover, the larger wear surfaces show smooth and stratiform structures. This also indicates that the material had been hard and brittle after deep cryogenic treatment.

Therefore, the effects of deep cryogenic treatment on wear mechanisms are significant. The shape of wear particles changes from slip tongue to stratification.

Figure 7 shows the wear profile for the SCM 415 disks. It is seen from this figure that the depth of the wear track is only $5 \mu \mathrm{m}$ for SCM415 with Carburizing-Tempering. Moreover, the phenomenon of material transfer can be found. However, the depth of the wear track can reach to $5.5 \sim 9.5 \mu \mathrm{m}$ for SCM415 with Carburizing-Deep cryogenic treatment-Tempering. This can be reasonable explained by that the martensitic transformation occurred after the deep cryogenic treatment.

Dynamic responses of microthermal expansion for the specimen under different composite heat treatments are shown in Figure 8. According to the results, Figure 9 shows the microthermal expansion for the specimen under the different heating temperatures. It is seen from this figure that the microthermal expansions are similar and smaller for the source SCM415 and the SCM415 with CarburizingDeep cryogenic treatment-Tempering. On the other hand, it shows larger than the other two cases for the SCM415 


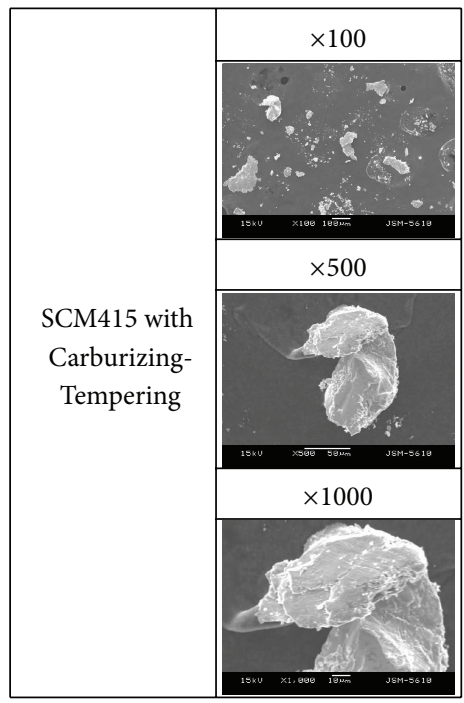

FIGURE 5: Representative SEM micrographs of wear particle for SCM415 with Carburizing-Tempering.

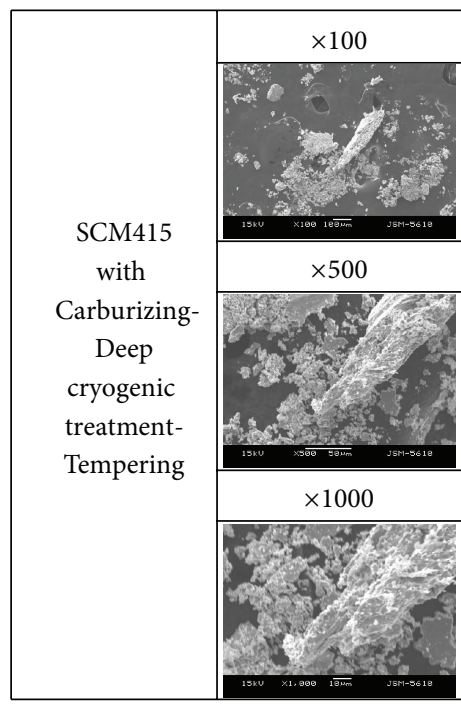

FIGURE 6: Representative SEM micrographs of wear particle for SCM415 with Carburizing-Deep cryogenic treatment-Tempering.

\begin{tabular}{|c|c|c|}
\hline & $75 \mathrm{~N}$ & $100 \mathrm{~N}$ \\
\hline Carburizing-Tempering & 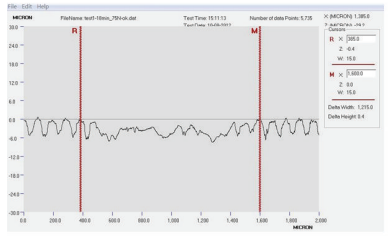 & $\left.\right|_{-1} \mid$ \\
\hline $\begin{array}{l}\text { Carburizing-Deep } \\
\text { cryogenic treatment- } \\
\text { Tempering }\end{array}$ & 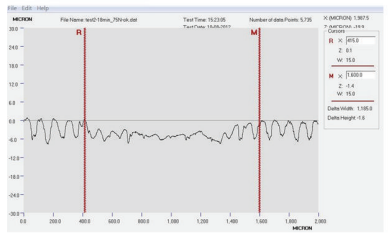 & 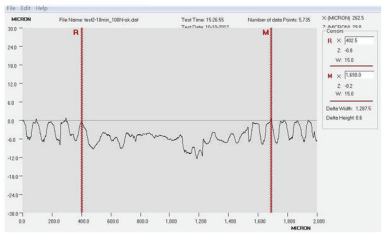 \\
\hline
\end{tabular}

FIGURE 7: The wear profile for the SCM415 disks. 


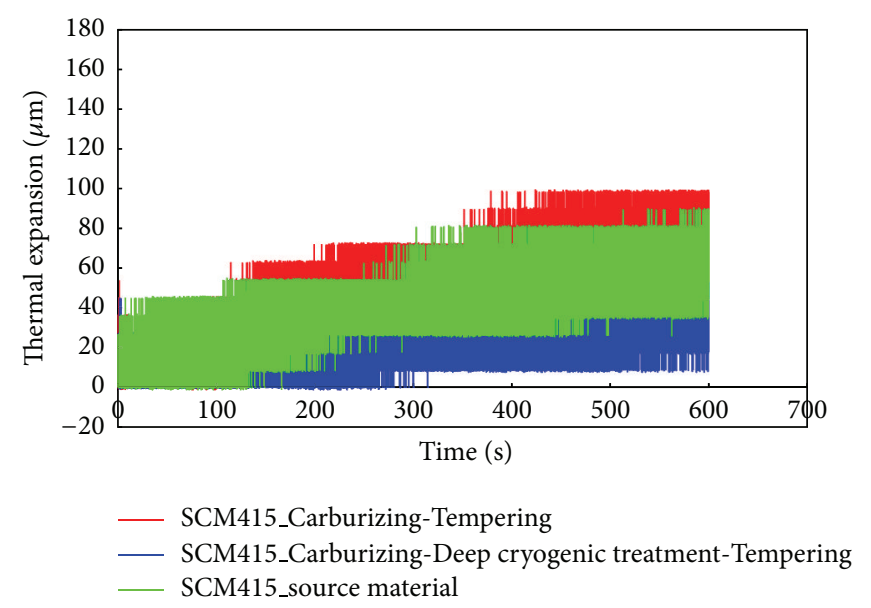

(a)

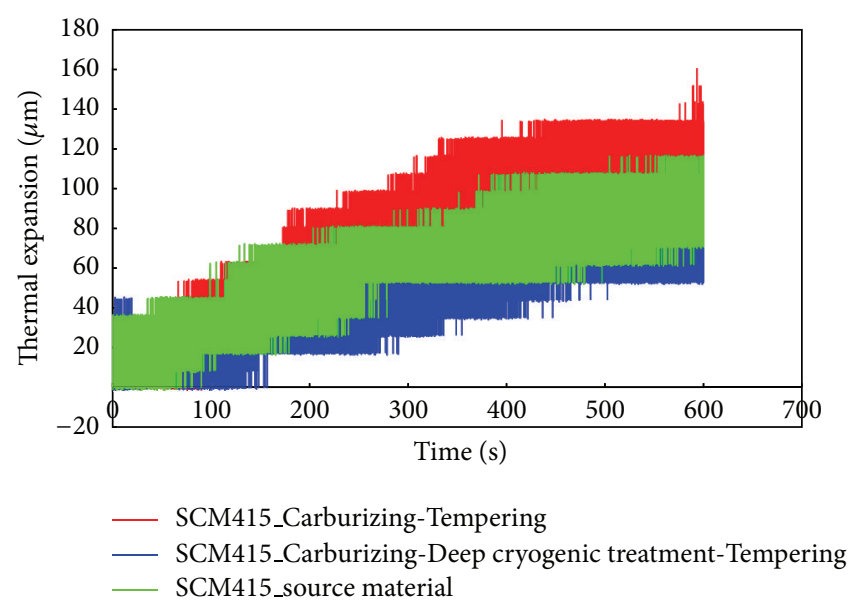

(b)

FIGURE 8: Dynamic responses of microthermal expansion for the specimen under different composite heat treatments: (a) the heating temperature of $100^{\circ} \mathrm{C}$ and (b) the heating temperature of $150^{\circ} \mathrm{C}$.
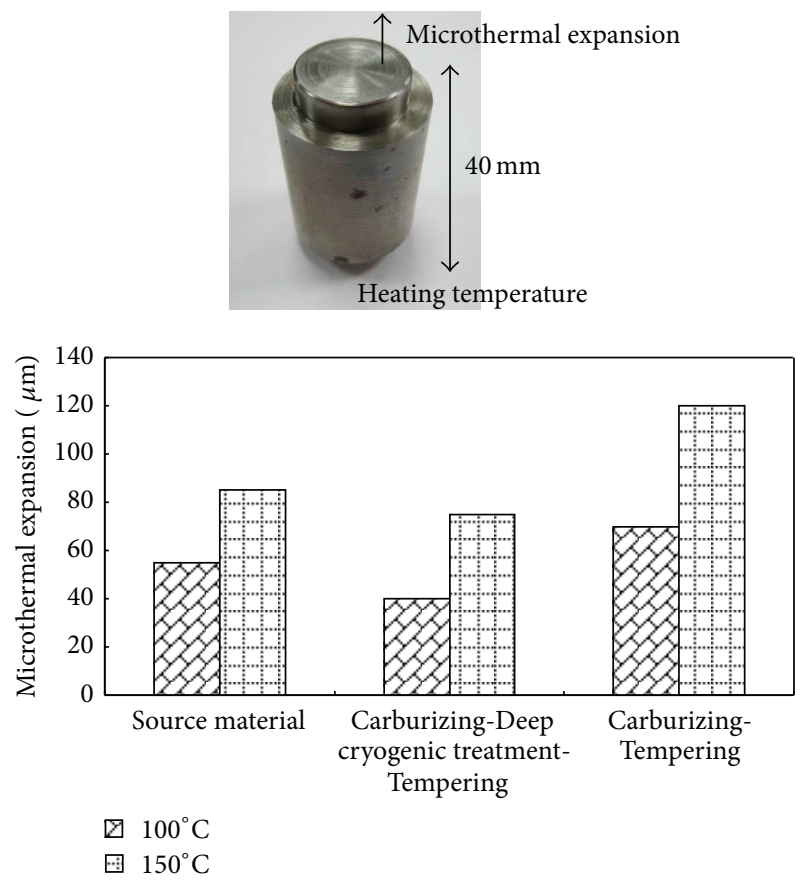

FIGURE 9: Microthermal expansion for the specimen under the different heating temperatures.

with Carburizing-Tempering. The differences between them are about $37 \sim 42 \%$. Therefore, the effects of deep cryogenic treatment on microthermal expansion are significant. It can decrease about 40\% microthermal expansion for the SCM415.

\section{Conclusions}

In this study, the effects of the deep cryogenic treatment on friction, wear mechanisms, and microthermal expansion of SCM415 have been investigated. From the experimental results and the SEM observations of the wear particles, the following conclusions have been drawn.

(1) The effects of deep cryogenic treatment on the values of friction coefficient and surface magnetization are insignificant.

(2) The martensitic transformation occurred after the deep cryogenic treatment. The material had been hard and brittle. As a result, the depth of the wear track is larger and the phenomenon of material transfer is few.

(3) Effects of deep cryogenic treatment on wear mechanisms are significant. The shape of wear particles changes from slip tongue to smooth stratification.

(4) The effects of deep cryogenic treatment on microthermal expansion are obvious. It can decrease about $40 \%$ microthermal expansion under the heating temperature of $100^{\circ} \mathrm{C}$.

\section{Conflict of Interests}

The authors declare that there is no conflict of interests regarding the publication of this paper.

\section{Acknowledgment}

The authors would like to express their appreciation to the National Science Council in Taiwan, for their financial support under Grant nos. NSC 101-2221-E-168-012 and NSC 102-2622-E-150-002-CC2.

\section{References}

[1] M. F. Carlson, B. V. Narasimha Rao, and G. Thomas, "The effect of austenitizing temperature upon the microstructure and mechanical properties of experimental $\mathrm{Fe} / \mathrm{Cr} / \mathrm{C}$ steels," Metallurgical Transactions A, vol. 10, no. 9, pp. 1273-1284, 1979. 
[2] H.-F. Chai and C. Laird, "Mechanisms of cyclic softening and cyclic creep in low carbon steel," Materials Science and Engineering, vol. 93, pp. 159-174, 1987.

[3] W. D. Callister, Material Science and Engineering: An Introduction, Wiley, New York, NY, USA, 3rd edition, 1994.

[4] D.-H. Huang and G. Thomas, "Structure and mechanical properties of tempered martensite and lower bainite in $\mathrm{Fe}-\mathrm{Ni}$ Mn-C steels," Metallurgical Transactions, vol. 2, no. 6, pp. 15871598, 1971.

[5] K. E. Thelning, Steel and Its Heat Treatment, Bofors Handbook, 1975.

[6] A. M. Nasreldin, M. M. Ghoneim, F. H. Hammad, R. L. Klueh, and R. K. Nanstad, "Effect of tempering on the toughness of a Cr-Mo bainitic steel," Journal of Materials Engineering and Performance, vol. 2, no. 3, pp. 413-420, 1993.

[7] T. P. Sweeney Jr., "Deep cryogenics: the great cold debate," Heat Treating, pp. 28-32, 1986.

[8] D. N. Collins, "Deep cryogenic treatment of tool steels: a review," Heat Treatment of Metals, vol. 23, no. 2, pp. 40-42, 1996.

[9] Y.-P. Chang, J.-P. Yur, H.-M. Chou, and H.-M. Chu, "Triboelectrification mechanisms for self-mated carbon steels in dry severe wear process," Wear, vol. 260, no. 11-12, pp. 1209-1216, 2006.

[10] Y.-P. Chang, H.-M. Chu, and H.-M. Chou, "Effects of mechanical properties on the tribo-electrification mechanisms of iron rubbing with carbon steels," Wear, vol. 262, no. 1-2, pp. 112-120, 2007.

[11] Y.-P. Chang, Y.-Y. Hung, L.-M. Chu, J.-P. Yur, and C.-H. Lin, "The surface magnetization approach on assessing tribological properties of steels with different TiN coatings," Proceedings of the Institution of Mechanical Engineers J, vol. 223, no. 4, pp. 715722, 2009.

[12] Y.-P. Chang, J.-H. Horng, J.-P. Yur, L.-M. Chu, and Y.-C. Hwang, "The surface magnetization approach on assessing the tribological properties of iron sliding against iron coated with pure tin and with a tin composite," Proceedings of the Institution of Mechanical Engineers J, vol. 225, no. 12, pp. 1199-1208, 2011. 

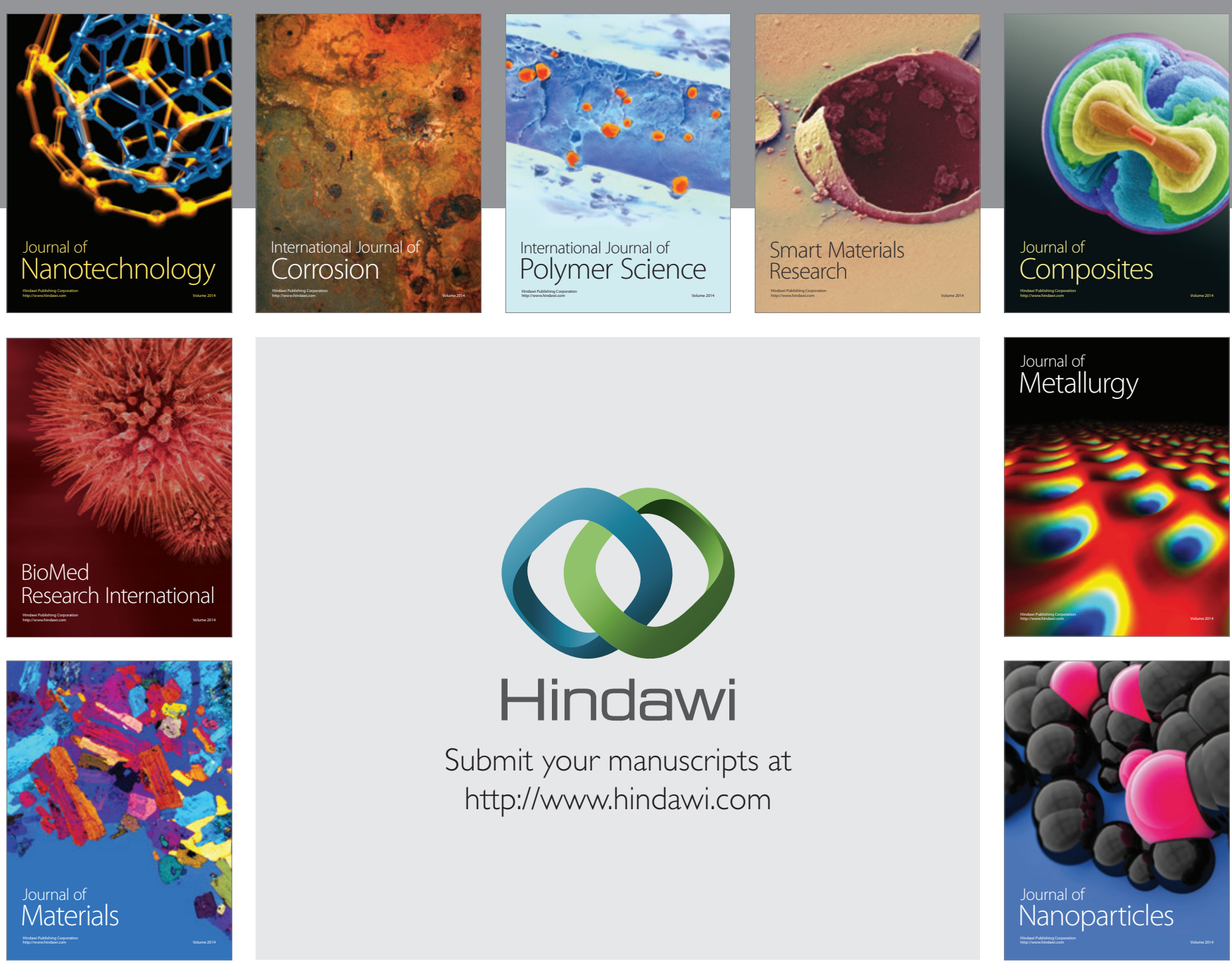

Submit your manuscripts at http://www.hindawi.com
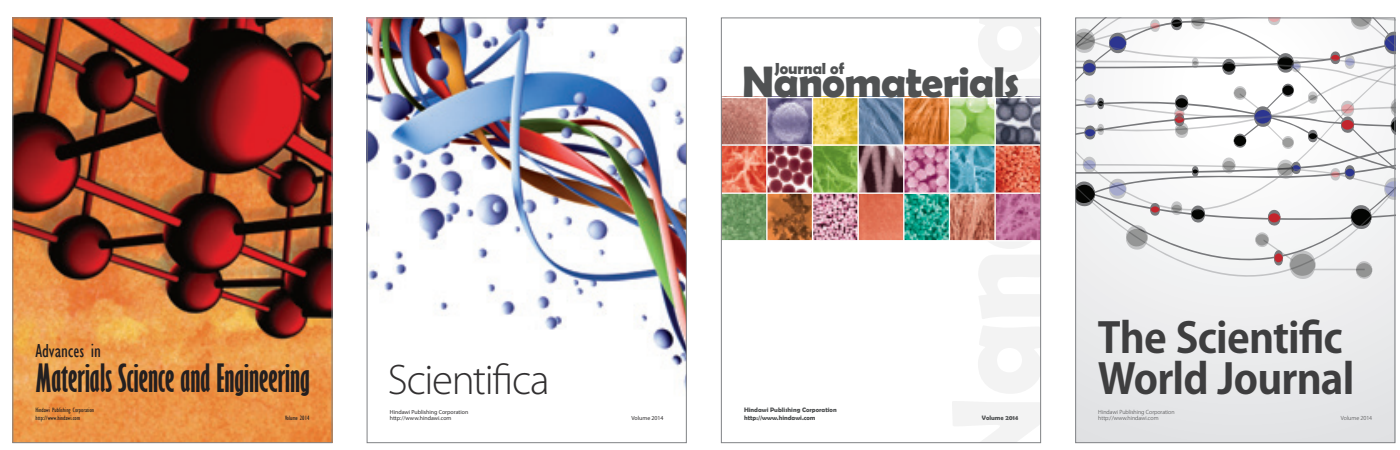

\section{The Scientific World Journal}
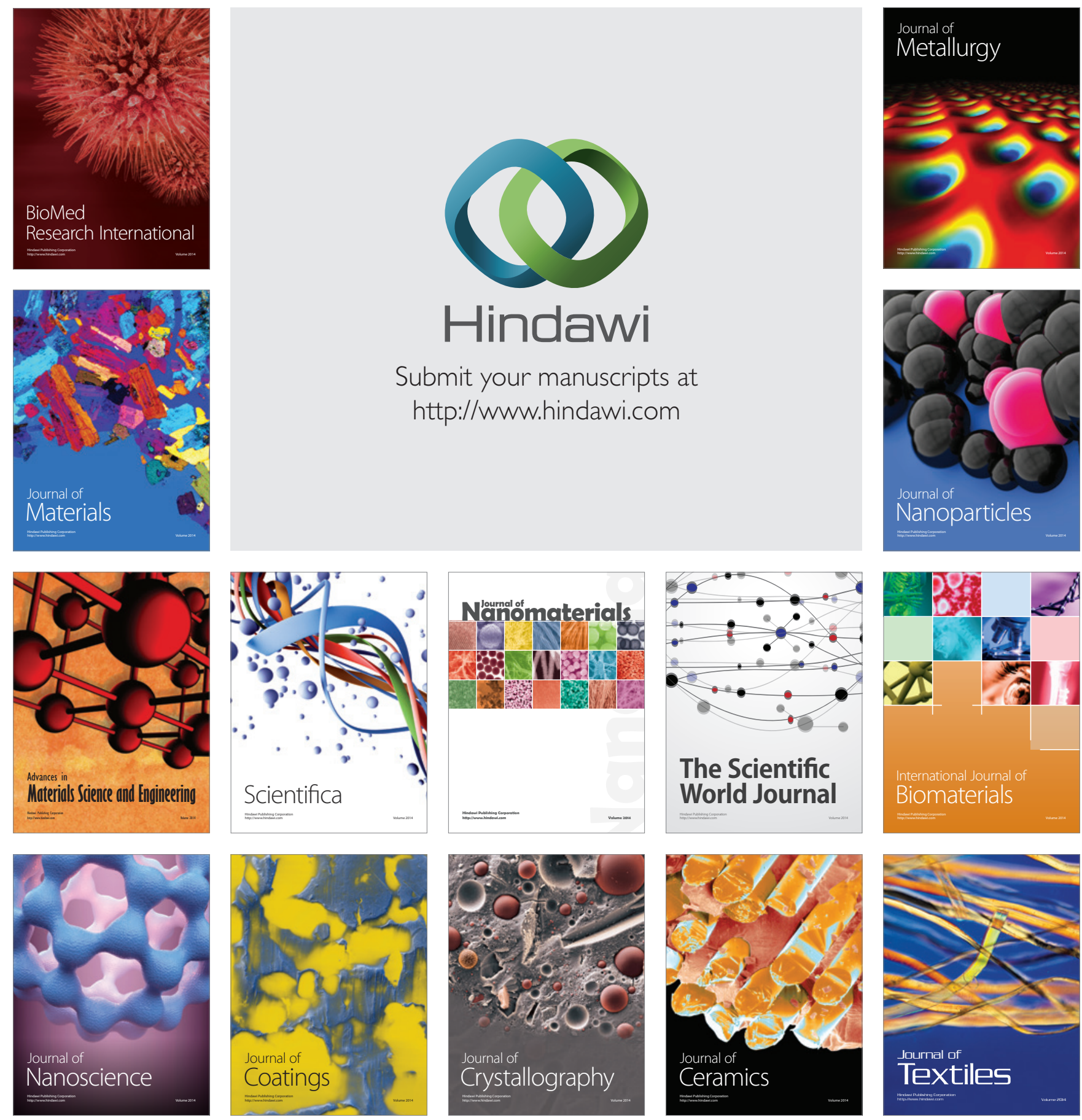